\title{
Reabilitação Ambiental no Igarapé da Fortaleza - O Parque do Igarapé e seu Paisagismo Ecológico
}

\author{
DOS SANTOS, Géssica Nogueira ${ }^{1}$ \\ MEDEIROS, José Marcelo Martins² \\ ${ }^{1}$ Acadêmica do curso de especialização REABILITA, FAU-UnB, e Mestranda do Programa de Pós-graduação em \\ Desenvolvimento Regional, Universidade Federal do Amapá, Macapá, Brasil. gessicanogueira@live.com \\ ${ }^{2}$ Doutorando do Programa de Pós-Graduação em Arquitetura e Urbanismo, FAU - UnB, Professor efetivo da \\ Universidade Federal do Amapá, Macapá, Brasil. medeirosjose@unifap.br
}

\begin{abstract}
Resumo
Este artigo analisou a área do Igarapé da Fortaleza, na divisa dos municípios de Macapá e Santana, no Amapá, na região amazônica brasileira, buscando uma nova solução urbanística que harmonizasse a atividade econômica existente no local (relacionada à venda de pescado, crustáceos e açaí) com o meio urbano e natural. A metodologia utilizada nesta pesquisa baseou-se primeiramente em um diagnóstico completo da área de estudo, realizada através de levantamentos in loco e entrevistas, cujos dados coletados e compilados resultaram em mapas temáticos, realizados nos software ArcGis, CoreIDRAW e Auto-Cad. A segunda etapa foi um levantamento bibliográfico do arcabouço conceitual do planejamento ambiental, que serviu de inspiração para a etapa final: a proposição de um parque com enfoque ecológico, o "Parque do Igarapé", com espaços tematizados pela cultura local, como a pesca artesanal de camarão e extrativismo de açaí.
\end{abstract}

Palavras-Chave: Paisagismo ecológico; Igarapé da Fortaleza; APA da Fazendinha.

\begin{abstract}
This paper studied the area known as Igarape of Fortaleza, a wetland located in the Brazilian Amazon, in the state of Amapa, between the cities of Macapá and Santana. The objective was to find a new urban solution that can cope with the existing economic activities (fishing and collecting acai berries) with the urban and natural environment. The methodology used was primarily based on a full diagnosis of the study area, conducted through surveys and interviews on site. The data were collected and compiled and resulted in thematic maps made in ArcGIS, CoreIDRAW and Auto-Cad softwares. The second step was a literature review of the conceptual theme of environmental planning, which served as inspiration for the final step: the proposition of ecological based park, the "Park of Igarape", that included open spaces that celebrate local culture, as the manual shrimp fishing and the extraction of acai berry.
\end{abstract}

Key-Words: Ecological landscape, wetland lgarape da Fortaleza, APA da Fazendinha. 


\section{Introdução}

O planejamento da paisagem nasce junto à necessidade de compreender as mudanças que ocorrem no meio natural devido às ações antrópicas, sendo essas ações possíveis geradoras de danos ambientais. O Igarapé da Fortaleza, afluente do caudaloso Rio Amazonas, é interligado com diversas ressacas (pântanos alagados) de Macapá e Santana, inclusive com a Lagoa dos Índios onde está localizada sua nascente. Além da relevância ecológica, possui importante atividade comercial, a qual mesmo com sua precária área portuária recebe embarcações que trazem diversas mercadorias, principalmente pescados, camarões e açaí. Destaca-se que muitos dos trabalhadores desta atividade residem na localidade, frequentemente em habitações improvisadas. A necessidade de intervenção urbana na área é eminente, sendo essencial a proposição de novos projetos para assegurar necessidades básicas a seus habitantes.

Para requalificação urbana e ambiental da área propõe-se um projeto de um parque urbano com a intenção de harmonizar a atividade econômica, o meio antrópico e o meio natural. Servirá para potencializar o turismo além de ajudar na conscientização dos moradores da comunidade do Igarapé da Fortaleza da importância ambiental do ecossistema amazônico. O projeto tem intenção de ser a "porta de entrada" da Área de Proteção Ambiental da Fazendinha, provindo melhorias infraestruturais para a toda a região.

\section{Problemática de habitação das várzeas urbanas - o caso do Igarapé da Fortaleza}

Localizada na divisa dos municípios mais populosos do Amapá, e delimitada ao sul pelo maior rio do mundo (figura 1), a comunidade do Igarapé da Fortaleza vivencia um cenário de desequilíbrio ambiental. A ocupação urbana desorganizada cresce e com ela a supressão vegetal e a geração de resíduos poluentes que afetam o curso hídrico, o ciclo natural das espécies e o micro clima.
Figura 1: Imagem por satélite da área de intervenção e entorno.

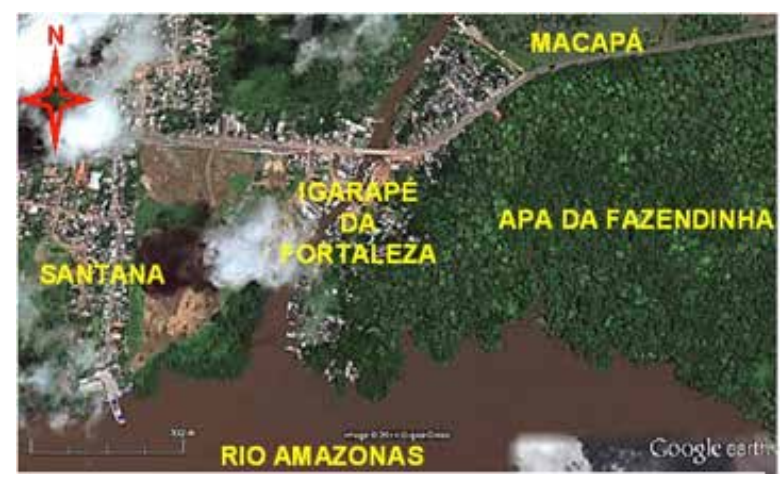

Fonte: Google Earth, 2013.

Na margem direita do Igarapé da Fortaleza existe uma área portuária pertencente ao munícipio de Santana e na margem esquerda existe a área de preservação ambiental da Fazendinha (APA da Fazendinha), uma unidade de conservação com área de 136,59 ha, marcada pela presença de cursos d'água e pela floresta densa de várzea. As espécies arbóreas mais representativas são: açaizeiro (Euterpe oleracea), pau-mulato (Calycophyllum spruceanum), seringueira (Hevea brasiliensis), andiroba (Carapa guianensis) e pracuúba (Mora paraensis).

Atualmente existem 1.299 moradores na APA da Fazendinha segundo levantamento realizado pela Secretaria de Meio Ambiente do Estado do Amapá realizado no ano de 2013 , constatando um grande crescimento populacional nos últimos anos. Em 1995 eram 77 famílias, em 1998 havia 110 famílias e em 2013 já eram 568 famílias. Essas pessoas vivem em condições de vulnerabilidade social, com a falta de serviços públicos básicos, gerando um ambiente propício a práticas ilícitas como o tráfico de drogas (figura 2).

Figura 2: Moradias dentro da APA da Fazendinha

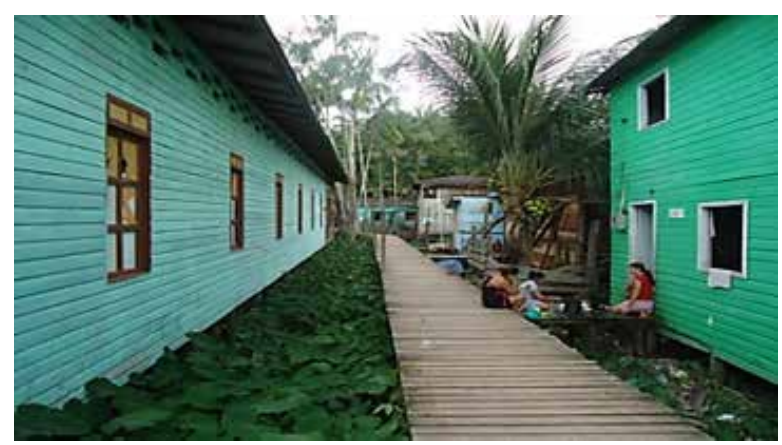

Fonte: Foto do autor, Dos Santos (2013). 


\section{Planejamento Ambiental aliado ao Paisagismo Ecológico}

Um dos primeiros autores a inserir estudos ecológicos no planejamento urbano foi lan McHarg (1920-2001) com o livro Design with Nature (1969), que foi um percursor do planejamento ambiental. Neste livro, o autor aplicou o novo conhecimento derivado da ecologia para ações concretas no planejamento urbano, como por exemplo, o problema da inserção de vias expressas na paisagem. Suas práticas inseriram-se no planejamento urbano a partir da ideia de que a tomada de ações sempre deveria contar com o estudo prévio dos cursos d'água, da topografia, da vegetação, da fauna, entre outros.

Com a conscientização da necessidade da conservação ambiental, os princípios ecológicos se voltam ao planejamento da paisagem urbana, considerada agora como parte integrante da natureza, resultado de uma série de trabalhos que reconhecem e analisam os processos naturais no ambiente urbano. Conforme Spirn (1995), a natureza é um continuum, com a floresta em um dos polos e a cidade no outro. Os mesmos processos naturais operam na floresta e na cidade. A cidade não é nem totalmente natural nem totalmente artificial, $\mathrm{e}$ a desconsideração dos projetos naturais na cidade é, e sempre será tão custosa quanto perigosa.

Conforme Franco (2001), as ações de planejamento ambiental devem transcender os limites políticos, levando em conta os limites das bacias hidrográficas de maneira ecossistêmica. Para esta pesquisadora o planejamento ambiental:

"[...] é todo planejamento que parte do princípio da valoração e conservação das bases naturais de um dado território com base de auto-sustentação da vida e das interações que a mantém, ou seja, das relações ecossistêmicas" (FRANCO, 2001, p.35).

Já para Hurtado et al (1980) o planejamento ambiental é:

"O processo político, tecnológico, constitucional, jurídico e educativo, através do qual o homem e a sociedade deverão tomar as melhores alternativas de transformação; por outro lado, para avaliar os níveis de comprometimento das ações antrópicas visando definir as intervenções e os manejos adequados às especificidades dos ambientes para preservar os ecossistemas e conservar o ambiente sadio, em benefício das gerações humanas" (HURTADO et al apud ABSY, 1997, p. 8).

Segundo Romero (2001) uma consequência da expansão urbana no Brasil tem sido a redução de áreas com vegetação nativa devido às intervenções que desconsideram completamente os elementos naturais da paisagem. A prática da arquitetura e do desenho urbano concretiza-se sem considerar os impactos que provocam no meio ambiente, repercutindo não somente no desequilíbrio do meio, como também no conforto e na salubridade da população urbana.

Romero (2000) afirma que o desenho dos espaços deve ser condicionado e adaptado às características do meio, tais como topografia, revestimento do solo, ecologia, latitude, objetos tridimensionais e clima. Muitos dos problemas analisados seriam facilmente evitados com um traçado urbano apropriado ao clima e topografia do lugar. A importância do desenho dos espaços externos também é enaltecida por Romero (2001), partindo da ideia de que o espaço público deve ter uma forma definida, pensada e construída com tanta intenção como a de um edifício.

Segundo Andrade e Lemos (2015) um dos princípios para reabilitação ambiental de assentamentos urbanos é a revitalização urbana. Esta deve verificar a possibilidade de recuperação de áreas urbanas degradadas ou patrimônios culturais abandonados, recuperando-as e reaproveitando a infraestrutura existente, valorizando a cultura de sua cidade. Ainda segundo as autoras, essa iniciativa celebra a cidade viva, atraindo novos moradores, comércio e atividades para a vizinhança em áreas abandonadas.

A necessidade de amenizar os grandes impactos ambientais causados pelas edificações nas cidades faz com que projetistas criem alternativas mais sustentáveis. O paisagismo ecológico é caracterizado por sua intenção conservacionista, onde é enfatizada a preservação dos recursos hídricos e a sustentabilidade do meio ambiente, em uma escala maior do que as usadas no paisagismo tradicional e tem como objetivo final a recuperação de ecossistemas parcialmente ou completamente devastados. 
Projetos dentro desta linha conceitual auxiliam e gerenciam a conservação do ecossistema em que o meio antrópico está inserido, logo promovem qualidade de vida a seus habitantes. A partir da instituição de um planejamento para conservação ecológica que contemple grandes áreas de paisagem, as chances de sobrevivência da biodiversidade tornam-se expressivamente maiores.

Quanto à metodologia, habitualmente os planejamentos ambientais são estruturados em fases de diagnóstico através de pesquisa e coleta de dados; fase de análise quando se identificam os potenciais e conflitos da área; e, ainda a fase de síntese, que implica no uso da informação obtida nas fases anteriores para a tomada de decisão correspondente à meta do planejamento.

Como exemplo deste conceito tem-se o projeto de intenção conservacionista do arquiteto Fernando Chacel para o Parque da Gleba E (1985), localizado na Barra da Tijuca no Rio de Janeiro (figura 3). Aárea de implantação do projeto encontrava-se devastada, causando a extinção de espécies do ecossistema da restinga, e a degradação do manguezal (CHACEL, 2001). Instituem-se então três modelos projetuais paisagísticos de intervenção, com o intuito de promover o manejo ambiental da área, são eles: o Modelo Mangue, o Modelo Restinga e o Modelo Parque. O primeiro baseado na recuperação e restauração do manguezal, o segundo objetivava recriar na paisagem um ecossistema similar ao original, próprio das restingas e áreas de transição com manguezais, e o Modelo Parque foi projetado de forma que a arborização implantada, formada por elementos originais da flora regional e de floração rica, "definisse o setor como um espaço aberto e colorido, de passeio e de convívio que caracteriza um parque." (CHACEL, 2001, p. 56).

Figura 3: Manguezais Restaurados no Parque da Gleba $\mathrm{E}$.

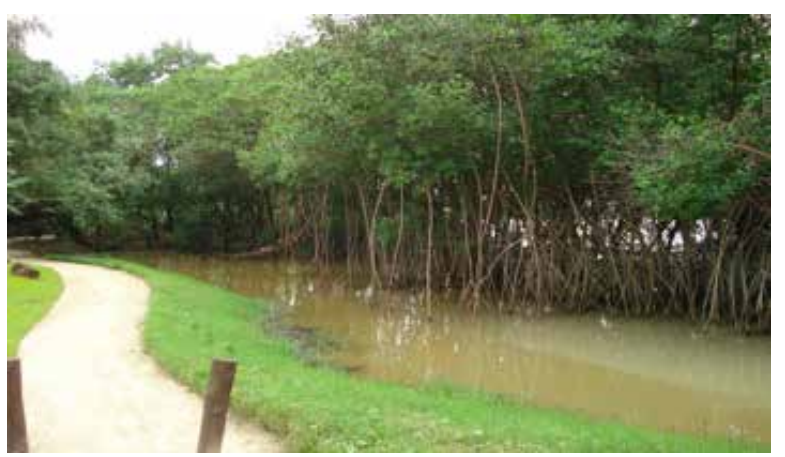

Fonte: Foto do autor, Medeiros (2013).

\subsection{Parques urbanos brasileiros com enfoque ecológico}

A experiência de parques urbanos com ênfase na conservação e restauração ambiental é uma tendência que ganha maior evidência a partir da década de 1980 no Brasil, juntamente com o movimento ambientalista. Estes projetos ecologicamente corretos contemplam serviços de lazer, cultura ou mesmo turismo e visam a recuperação de ecossistemas originais das áreas de implementação, degradados ou mesmo extintos.

No cenário nacional, Macedo e Sakata (2002) aprofundam as discussões sobre os espaços livres existentes nas cidades, verificando esses espaços como representantes de uma condição da vida cultural urbana. Analisando a temática dos parques urbanos atuais, eles explicam que estes surgem como requalificação dos espaços urbanos, principalmente nas áreas centrais das cidades, com a demanda crescente de espaços de recreação e lazer e com a introdução da dimensão ambiental.

Os parques acabam criando identidade vernácula à região, a partir de que são compostos por indivíduos paisagísticos próprios dos ecossistemas nativos, permitindo a apropriação simbólica natural pela população local e harmonizando usos antrópicos e meio natural.

Como exemplo destes modelos de parques, temos o Parque da Gleba E (1985), já mencionado anteriormente, considerado como primeiro projeto de intenção conservacionista ecológica do arquiteto paisagista Fernando Chacel, em parceria ao também arquiteto paisagista Sidney Linhares. O parque está localizado na Barra da Tijuca no Rio de Janeiro, às margens da Lagoa da Tijuca (figura 4).

Esse Parque, e o conjunto das demais áreas verdes previstas no projeto urbanístico, determinariam a formação de um "continuum" paisagístico capaz de conferir ao empreendimento, qualidades estéticas e de conforto climático, aliadas a ganhos bióticos compensatórios, decorrentes dos inevitáveis impactos causados pela implantação do projeto de desenvolvimento pretendido. (CHACEL apud. MEDEIROS, 2008, p. 31). 
Figura 4: Modelos mangue, restinga e parque associados e em contraponto com torreões multifamiliares, às margens da Lagoa da Tijuca.

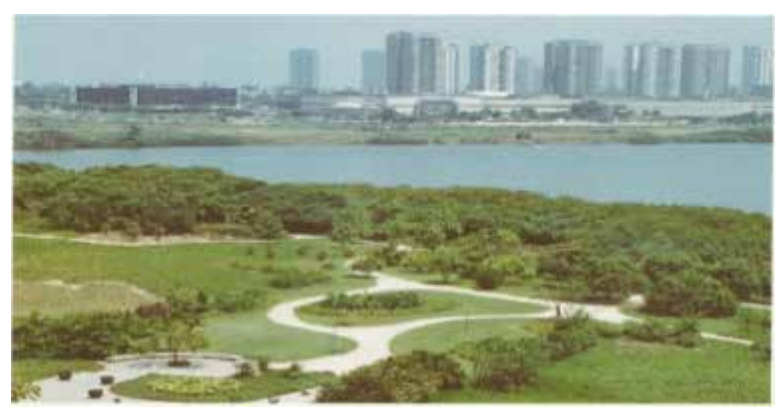

Fonte: CHACEL, 2001, p. 64.

Outro parque com enfoque ecológico é o Parque de Educação Ambiental Professor Mello Barreto (1995), também criado pela colaboração dos arquitetos paisagistas Fernando Chacel e Sidney Linhares, localiza-se adjacente à Gleba $\mathrm{E}$, na faixa marginal de proteção da Lagoa da Tijuca. Anteriormente à implantação do parque a área era residida por invasões responsáveis diretas pela degradação quase total do ecossistema.

A proposta projetual do parque buscou a recuperação do manguezal, e ainda dar ênfase a vegetação da flora litorânea, por meio de um jardim de bromélias, elementos da mata atlântica, e ainda por um recinto destinado a plantas da restinga, utilizando não apenas indivíduos específicos do ecossistema da Barra da Tijuca. O parque conta com caminhos e locais de parar e estar (figura 5), ciclovia, uma arena, o qual é ponto de concentração e dispersão dos visitantes, e dois píers de atracação para pequenas embarcações.

Figura 5: Contraste de vegetação arbórea e arbustiva.

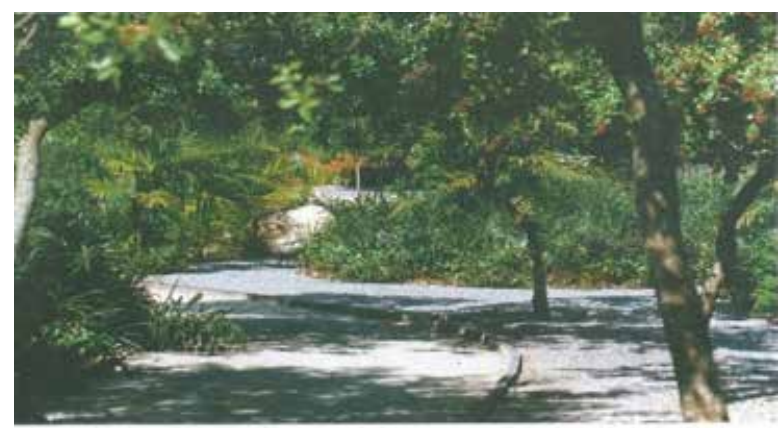

Fonte: CHACEL, 2001, p. 78.

Outro exemplo é o Parque Naturalístico Mangal das Garças (2005), situado às margens do rio Guamá, em Belém do Pará. O parque projetado pela arquiteta paisagista Rosa Grena Kliass foi implantado em uma área de aproximadamente 35.000 metros quadrados adjacente ao arsenal da marinha, área esta degradada anteriormente por corte e aterro do ecossistema. É um complexo de lazer, turismo, cultura e de resgate do meio ambiente, sendo tematizado pela representação da vegetação natural do Estado do Pará, suas macrorregiões florísticas, onde criaram-se três modelos: as florestas de terra firme, os campos e as florestas de várzea, onde promoveu-se a recuperação do aningal à beira rio, outrora devastado (figura 6).

Figura 6: Aningal e belvedere às margens do rio Guamá.

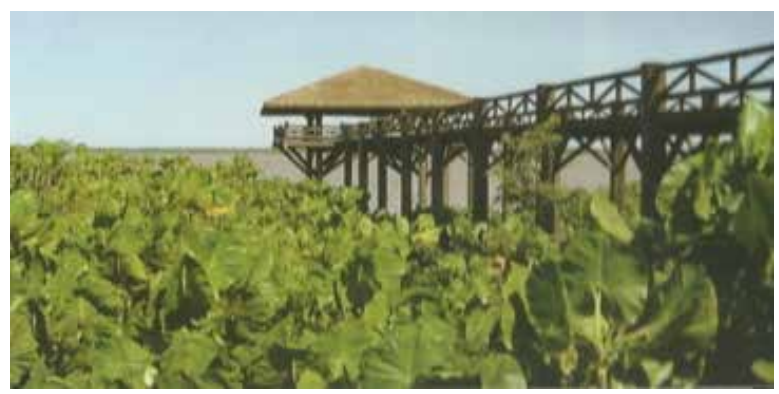

Fonte: MACEDO, 2010, p. 78.

Além de uma bela vista do rio Guamá, o parque possui elementos de animação como borboletário, aviário, mirante, lagos, restaurante, memorial, ponte, pergolado e orquidário. Sua dinâmica é dada a partir da água, elemento esse conduzido desde fontes e cascatas até os lagos do parque fluindo por linhas d'água (figura 7).

Figura 7: Arranjo geral do parque naturalístico Mangal das Garças.

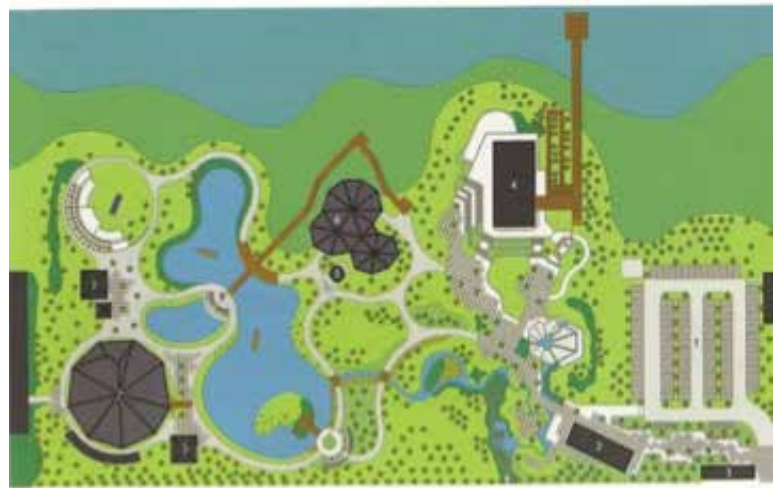

Fonte: MACEDO, 2010, p. 78. 


\section{Diagnósticos e mapas temáticos}

A área do Igarapé da Fortaleza (figura 8) foi estudada em sua totalidade, as relações entre as esferas ambiental, social, econômica e política bem como o diagnóstico dos impactos, potencialidades e vulnerabilidades. Criou-se um perfil dos moradores da área através de entrevistas com grupo de habitantes da comunidade, além do levantamento de dados que resultaram em mapas temáticos, realizados no software ArcGis e finalizados no software CorelDRAW.

Figura 8: Igarapé da Fortaleza com embarcações.

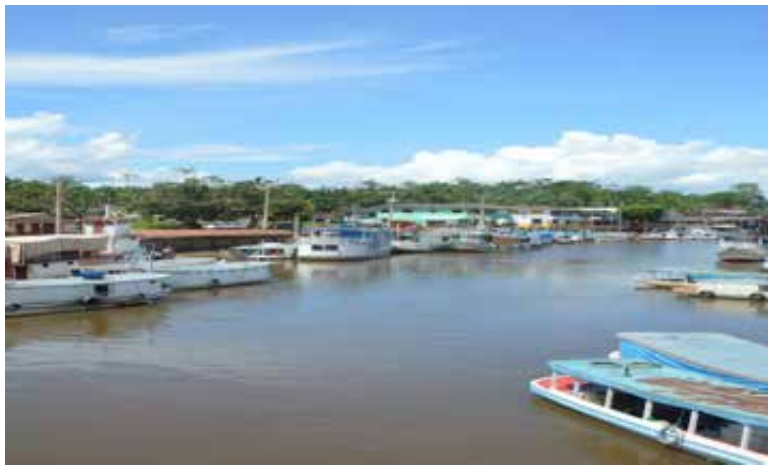

Fonte: Foto do autor, Dos Santos (2013).

No primeiro mapa temático (figura 9) pode-se observar pontos importantes como duas escolas de ensino fundamental, restaurantes, posto de gasolina, etc. $\mathrm{Na}$ área portuária existem algumas empresas que trabalham com exportação de pescado, açaí e castanhas.

Figura 9: Mapa temático referente aos pontos e percursos principais na área.

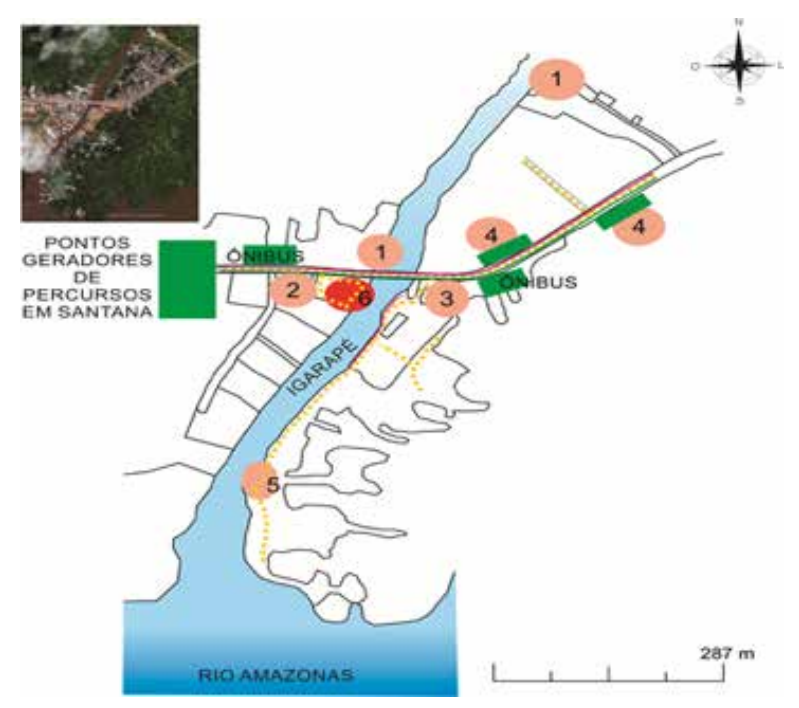

\section{Legenda}

Pontos importantes

1 - Restaurante

2 - Posto de gasolina

3 - Posto de fiscalizacăo (desativado)

4 - Escola

5 - Base da SEMA

- Vias principais geradoras de percursos

Fontes principais geradoras de pereursos

" " " Principais percursos de pedestres

- Areas impermeabilizadas

Elementos focos de animaçã̃o do espaço 6 - Venda de pescado

Fonte: Imagem dos autores, 2013.

Há ainda elementos que geram aglomeração de pessoas como lojas de venda de pescado e açaí, paradas de ônibus na rodovia Salvador Diniz (AP010) que liga a zona sul de Macapá à Santana e ainda um cais na margem esquerda do Igarapé, onde atracam-se embarcações de pequeno e médio porte para o desembarque de passageiros em geral vindos das ilhas do Pará e da ilha de Santana.

No Mapa Temático de Cenários Visuais (figura 10), foram identificados os "visuais de interesse", onde temos o próprio curso d'água com suas habitações ribeirinhas; os "marcos visuais", como o portuário do Igarapé da Fortaleza e a ponte que liga os municípios de Macapá e Santana; além das "visuais desagradáveis" que são as habitações irregulares e pontos de acúmulo de lixo ao ar livre.

Figura 10: Mapa temático de cenários visuais.

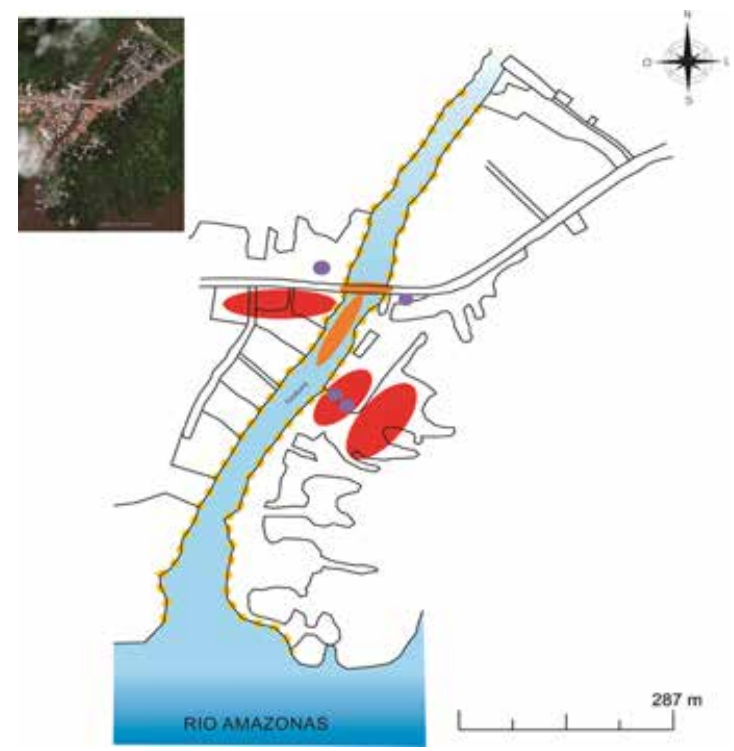




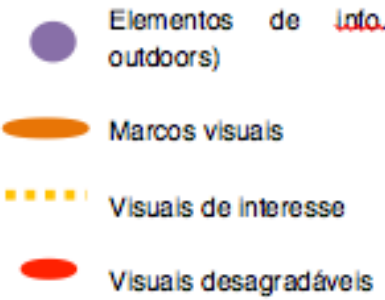

Fonte: Imagem dos autores, 2013.

A ausência de esgoto, sistema de coleta de lixo precário, e falta de fiscalização e de ações educativas são os grandes responsáveis pelo cenário de poluição da área. Em entrevista com grupo de moradores da área questionou-se quanto ao destino das águas servidas, mais de cinquenta por cento dos entrevistados acabam por escoar os dejetos para o igarapé.

Quando questionados sobre as atividades de lazer, responderam que iam à igreja, praticavam jogos com amigos e tomavam banho de rio. Mas a maioria se queixa de não existirem atividades de lazer adequadas e da sensação de insegurança na comunidade (gráfico 1).

Gráfico 1: Principais problemas existentes na comunidade.

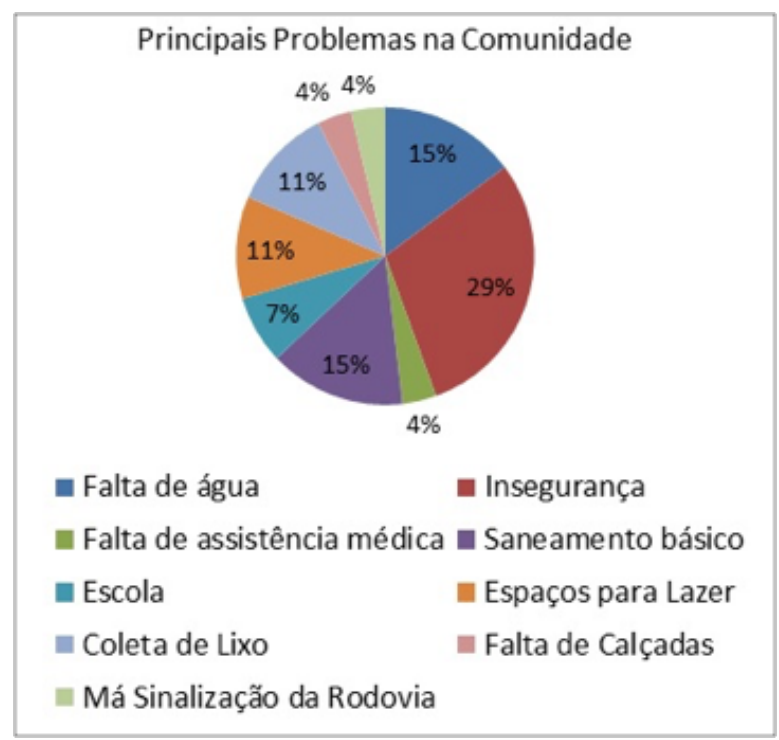

Fonte: Autores, 2013.

Foram questionados quais eram os desejos de infraestrutura da comunidade a resposta mais frequente foram "praça" e "posto policial" (gráfico 2).
Gráfico 2: Infraestrutura almejada pela comunidade.

Desejos de Infraestrutura para a Comunidade
$=$ Campo de Futebol
= Praça
= Posto de Saúde
= Posto Policial
= Escola
= Esgoto
= Melhorias na Rede Geral de Água Canalizada
= Coleta de Lixo Regular

Fonte: Autores, 2013

Perguntou-se ainda se eles gostavam de morar na comunidade e quase a totalidade disse que sim. Já o que menos gostam é principalmente o fato de se sentirem inseguros no local, da poluição da área e da distância dos centros urbanos, onde estão os serviços públicos. Com base no que se conheceu do local pode-se prever os impactos que a implantação de um parque ecológico causaria, além de necessitar de melhorias no fornecimento dos sistemas de água e eletricidade, seria necessário implantar sistema de esgoto e drenagem de águas pluviais, infraestruturas básicas inexistentes no local atualmente.

\section{O Projeto Parque do Igarapé}

A proposta de criar um parque com enfoque ecológico surge como estratégia de caráter sustentável para propiciar qualidade de vida a seus residentes. $\mathrm{O}$ projeto foi desenvolvido em três etapas: Plano conceitual, Partido e Anteprojeto.

Aárea proposta é um pouco menor que oito hectares, e engloba parte da área da APA da Fazendinha (projeto de reconstituição ecogenética), parte da área do portuário do Igarapé da Fortaleza e ainda a ponte da rodovia Salvador Diniz (AP- 010) que liga os dois munícipios.

O programa de necessidades do parque conta com duas áreas de convivência, a primeira é a Praça do Camarão, composta pela Casa do Matapí, residência em madeira remanescente antes da intervenção onde ocorrerá a exposição da cultura local. A praça possuirá escultura temática, a feira do camarão e a praça de alimentação.

A segunda área de convivência é a Praça do Açaí, que possuirá memorial do açaí, que abordará a 
cultura extrativista artesanal do fruto, esculturas, feira com quiosques onde trabalharão as "batedeiras de açaí" e praça de alimentação.

As praças foram locadas paralelamente em margens diferentes do igarapé respeitando a divisão natural que já existe na área. Outro componente chave do programa é a feira de artesanato, que será sobre palafitas, tentando recriar a atmosfera da habitação tradicional. Junto à feira será locado um pequeno píer de acesso ao passeio náutico.

O programa conta ainda com borboletário, orquidário, mirante, passarela às margens do igarapé, uma segunda ponte apenas para pedestres, píer de atracação para pequenas embarcações, bloco administrativo, banheiros, pista de caminhada, estacionamentos e ponto de ônibus (figura 11). $O$ projeto também prevê a relocação das famílias que atualmente habitam na área de inserção do parque para área vizinha, onde deverá ser implantado um conjunto habitacional de interesse popular. Esse conjunto possibilitaria o uso noturno ao estacionamento do parque.

Figura 11: Projeto Paisagístico do Parque do Igarapé.

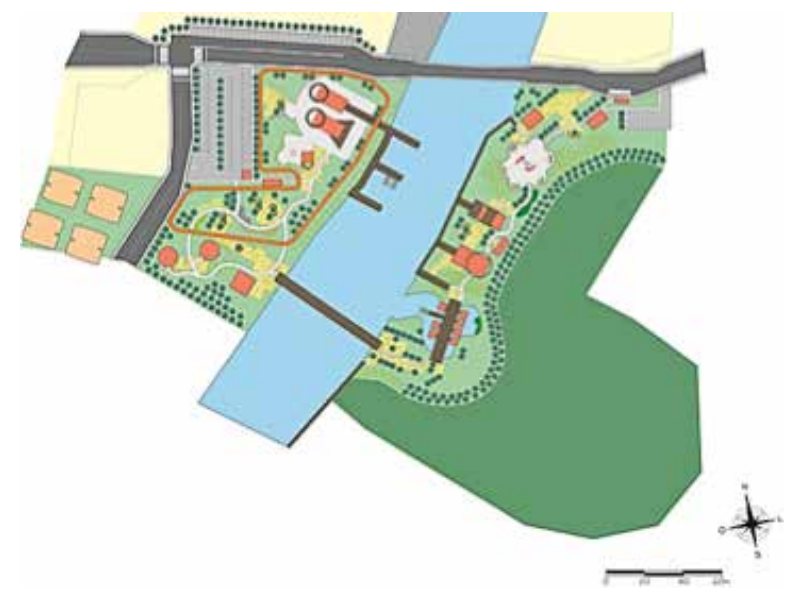

Conjunto Habitacional de Interesse Popular

Áreas de Convivio e Atraçóes

Calçada para caminhadas

Vegetaçấo Arbórea

Forraçoes

Estacionamento Proposto

Vias Principais de acesso

Deck de madeira

Curso d'água

Fonte: Imagem do autor, Dos Santos (2013).

\section{O Projeto Paisagístico}

A arborização do Parque do Igarapé é composta por espécies de médio e grande porte em sua maioria, com copas densas e em quase sua totalidade são nativas de tipos fisionômicos da paisagem do Amapá, são eles: a várzea (ecossistema natural onde está localizado o parque), o campo arbustivo periodicamente inundado e o cerrado associado a campo limpo.

As espécies foram plantadas em agrupamentos, as espécies que não fazem partes dessas disposições são o cedro (Cedrela odorata), a samaúma (Ceiba pentandra) e o açacu (Hura crepitans). O cedro foi disposto em pares sequenciais espaçados entre si para evitar o ataque de broca, comum em largos agrupamentos homogêneos da espécie, a samaúma foi disposta individualmente devido ao seu grande porte e diâmetro do tronco, e o açacu também disposto de forma individual por ser uma espécie dotada de acúleos, e foi locada apenas no limite do parque, em área destinada a reconstituição ecogenética, longe dos passeios. Natural da várzea, esta árvore possui rápido crescimento e é ideal para recompor a vegetação degradada.

Na mesma área de implantação do açacu, foram locadas espécies como o pau-mulato (Calycophyllum spruceanum), a andiroba (Carapa guianensis) e a ucuúba (Virola surinamensis). Outras espécies nativas da várzea presentes no parque são o Jenipapo (Genipa americana), a Mamorana (Pachira aquatica), a Pracuúba (Mora Paraensis), o Pente-de-macaco (Apeiba tibourbou), o Taperebá (Spondias mombin), o Tachi (Triplaris weigeltiana) que ocorre no campo arbustivo periodicamente inundado amapaense, a Mangaba (Hancornia speciosa) ocorrente no o cerrado associado a campo limpo amapaense, e ainda o Urucum (Bixa orellana).

Com relação as palmeiras de várzea, propõe-se os açaizeiros (Euterpe oleraceae) e buritizeiros (Mauritia fleuxuosa), serão semeadas aleatoriamente criando concentrações homogêneas de cada espécie. Dentre as dezenove espécies arbóreas apenas duas são exóticas, são elas a palmeira juçara (Euterpe edulis), natural da mata atlântica, que diferente do açaí e do buriti não possuí a característica de perfilhamento possibilitando a criação de aléias, e a segunda espécie exótica é a palmeira areca-delucuba (Dypsis madagascariensis), que devido a 
característica de não ocorrer frutificação da espécie em áreas super úmidas foi utilizada no sombreamento de bancos e aléias. Nos estacionamentos utilizou-se a lofantera-da-amazônia (Lophanthera lactescens). Quanto à vegetação herbácea têm-se jardins em formas amebianas onde se utilizou espécies nativas do ecossistema amazônico como o lírio-da-pazdo-amazonas (Spathiphyllum cannaefolium), a helicônia-papagaio (Heliconia psittacorum), além de espécies medicinais e exóticas. Há ainda o jardim aquático de vitória-régia (Victoria regia), próximo a feira de artesanato.

\section{Conclusão}

As discussões a respeito da sustentabilidade ambiental crescem no cenário mundial, garantir a sobrevivência de ecossistemas e atender as demandas do crescimento populacional acelerado e seu consumo desenfreado tem se mostrado uma equação difícil de equilibrar. No presente trabalho foram vistos alguns planos e projetos considerados técnicas ambientalmente responsáveis que intencionam dar um start no processo de balanceamento desta equação. $O$ paisagismo ecológico e o planejamento ambiental foram discutidos como meios de manejo do plano de ação para a área da comunidade do Igarapé da Fortaleza e endossam projetos de parques ecológicos brasileiros que dinamizam esses conceitos, valorizando áreas verdes e contemplando a sociedade com infraestrutura de lazer, cultura e esporte, além de promover a educação ambiental.

Na divisa das duas maiores cidades do Amapá, o Igarapé da Fortaleza além da sua importante função ambiental, por estar ligado com as principais áreas de ressaca de Macapá e Santana e ser um dos limites de uma Área de Proteção Ambiental, sua área portuária apresenta importante atividade comercial, a expressiva comercialização de pescado e açaí, os produtos são base da alimentação local. Com o diagnóstico e análise dos dados da área de estudo, a comunidade do Igarapé da Fortaleza, a partir da problemática da degradação e poluição por ações antrópicas inconscientes da APA da Fazendinha e o Igarapé, identificou-se as fragilidades e potencialidades da área, possibilitando a criação de um plano de ação que pudesse mudar essa realidade, originando-se assim o projeto do Parque do Igarapé.
O parque do Igarapé visa à harmonização das atividades já existentes na área com o manejo sustentável do curso hídrico e da APA. As atividades de venda de pescado e açaí foram organizadas em duas áreas de convivência, cada uma em uma margem do igarapé. A parte da APA a ser recuperada enfrentará o remanejamento da população para um sítio vizinho. Esta população virá a usufruir da infraestrutura proposta pelo parque.

Aplicaram-se conceitos do paisagismo ecológico na concepção projetual, além de estratégias para a promoção da educação ambiental. O parque do Igarapé retratará a cultura da própria comunidade, seja nos seus usos, vegetação e elementos plásticos. O novo espaço público será inserido de forma condizente com a realidade local, assim seus usuários se sentirão ligados de forma intrínseca ao sítio, apropriando-se da área simbolicamente.

\section{Referências}

ABSY, M. Demanda de instrumentos de gestão ambiental, zoneamento ambiental. Documento desenvolvido na implementação do Projeto Tecnologias de Gestão Ambiental, RGA, do Programa Nacional do Meio Ambiente (PNMA). Ibama, Brasília, 1997.

ANDRADE, L. e LEMOS, N. Qualidade de projeto urbanístico / sustentabilidade e qualidade da forma urbana. In: BLUMENSCHEIN, R. et al. (Org.). Avaliação da qualidade da habitação de interesse social : projetos urbanístico e arquitetônico e qualidade construtiva. FAU- UnB. Brasília, 2015.

CHACEL, F. Paisagismo e ecogênese. Fraiha. Rio de Janeiro, 2001.

FRANCO, M. Planejamento ambiental para a cidade sustentável. Annablume FAPESP, São Paulo, 2001.

HURTADO, A. G. e Acuña, E. C. Las Variables Ambientales en la Planificación del Desarrollo. Estilos de desarrollo y medio ambiente en America Latina. Fundo de la Cultura Económica, México, 1980.

MACEDO, S. e SAKATA, F. Parques Urbanos no Brasil. Edusp. São Paulo, 2002.

MCHARG, I. Design with Nature. John Wiley \& Sons, New York.], 1969. 
MEDEIROS, J. Visões de um Paisagismo Ecológico na Orla do Lago Paranoá. Dissertação (Mestrado) - Universidade de Brasília (UnB), Brasília, 2008.

MEDEIROS, J. e DOS SANTOS, G. Cenários de um Paisagismo Ecológico no Igarapé da Fortaleza - O Parque do Igarapé. In: $12^{\circ}$ Encontro Nacional de Ensino de Paisagismo em Escolas de Arquitetura e Urbanismo do Brasil (ENEPEA). Vitória, 2014.

ROMERO, M. Princípios Bioclimáticos para o Desenho Urbano. ProEditores. São Paulo, 2000.

.AArquitetura Bioclimática do Espaço Público. Editora Universidade de Brasília. Brasília, 2001.

SPIRN, A. O Jardim de Granito: a natureza no desenho da cidade. Edusp, São Paulo, 1995. 